\title{
Exploring Challenges in Integrating ICT in Secondary Mathematics with TPACK
}

\author{
Dorian Stoilescu \\ University of Western Sydney \\ <d.stoilescu@uws.edu.au>
}

\begin{abstract}
This paper describes challenges encountered by three experienced secondary mathematics teachers when they try to integrate ICT in their classrooms. This study is based on the four dimension framework developed by Niess: 1) overarching conceptions of integrating ICT, 2) knowledge of instructional strategies and representations for teaching, 3) knowledge of students' knowledge of technology; and 4) knowledge of curriculum and curriculum materials that integrate technology with learning. By using this analysis, we explore the challenges that teachers face on each of the four levels of integration ICT and suggest ways of improving these strategies in mathematical instruction.
\end{abstract}

Keywords: Integrating ICT in mathematics; mathematics secondary teachers; teacher professional development; Technological Pedagogical Content Knowledge.

\section{Introduction}

Using ICT in education has been praised by many educators for offering support for performing differentiated instruction, opportunities for collaboration, and ways to engage through diverse paths of teaching and learning (Kelly \& Tangney, 2006; Kaput, Noss \& Hoyley, 2008; Stoilescu, 2011, forthcoming). While the first attempts to describe the effects of integrating technology in classrooms were oriented mostly towards the direct interactions between the learners and technologies, the problems of educating and helping teachers themselves to use technology was deemed as crucial. Overall, if educators do not view the use of technology as a universal panacea and if they are knowledgeably and flexibly adapting ICT to specific classroom settings, ICT might have major benefits for classrooms (Heid, 2005; Fuglestad et al., 2010).

More specifically, in the case of mathematics education, integrating ICT was often emphasized as having a major contribution to support learning and teaching. According to Drijvers, Kieran, and Mariotti (2010), mathematics teachers can use technology to create opportunities for inquiries, modelling and communication. More specifically, the National Council of Teachers of Mathematics (NCTM) has been promoting since the beginning of the 1980s the process of integrating technology in mathematics classrooms. The NCTM (2000) recommends that teachers use appropriate computer technology in mathematics classrooms in 
order to improve the quality of learning. "Students can learn more mathematics, more deeply with the appropriate and responsible use of technology" (NCTM, 2000, p. 25).

In spite of the hype, there are serious challenges and failures in adequately using ICT in classrooms. Sometimes, the creation of software creates challenges in establishing an adequate agency representing learners. For instance, some mathematics software might prevent students from establishing proper connections and proofs (Van Herwaarden \& Gielen, 2002). Likewise, Hoyles and Noss (2003) report cases where students believed that, by having computers in classrooms, there was no need to think mathematically. Another challenge of software agency was reported where students' use of the software becomes rigid as students cannot have the support of the initial authors to modify the product (Magala, 2006). Not being flexible enough for deep inquiries and complex interactions with learners, in this case, the software becomes a barrier between learners and software authors.

In order to help teachers integrate ICT in classrooms, Koehler and Mishra (2009) introduced the TPACK framework, as an accommodating and supportive theoretical aid to help teachers integrate technology in their classrooms.

In studying preservice teachers in mathematics, Niess (2008) recommends that the TPACK framework should take into account four important aspects:

1. An overarching conception of what it means to teach a particular subject, integrating technology in the learning process;

2. Knowledge of instructional strategies and representations for teaching particular topics with technology;

3. Knowledge of students' understandings, thinking, and learning with technology; and

4. Knowledge of curriculum and curriculum materials that integrate technology with learning.

This article is based on Niess' design framework and explores difficulties encountered by teachers when they attempt to use ICT in secondary school mathematics classrooms. This research paper describes the challenges that mathematics teachers have in integrating technology in teaching mathematics. The goals of this research are: to understand existent challenges in integrating technology through pedagogical models of knowledge. The main research questions explored here was: What difficulties do teachers have when they try to integrate technology into mathematics classrooms? 


\section{Literature Review}

Integrating ICT in secondary mathematics has manifold benefits. Beyond the immediate advantages of using the software in manipulating quantitative data and software for the office (word processors, PowerPoint presentations, spreadsheets), technology provides students with the opportunity to simulate different complex scenarios, processes and phenomenon, to generate visualisations and explorations, and to connect dynamic notations, linked representations, and operations with symbols (Kaput \& Shaffer, 2002). Therefore, integrating technology in mathematics classrooms should not be simplistically perceived as using computers to avoid laborious calculations; rather it is a tool for the mind, representation and modelling. With adequate technology, Sangwin et al. (2010) argues that mathematics teachers can help their students to develop their metacognitive abilities.

Although researchers point out the potential of ICT to help mathematics education, this is not always easy to accomplish in practice. One of the reasons is that keeping up with the latest technological trends is very difficult for educators. For instance, educators such as Anderson (1992), Kaput (1992) and McRory (2006) have cautioned about the risk of ICT devices becoming obsolete in short time. In addition, because of the high cost of periodically purchasing software, there is a growing pressure for educators to produce better student learning outcomes.

Plair (2008) noticed that teachers that have been a long time in the field and were not trained to integrate technology, did not use ICT devices in their classroom. As well, Li (2007) noticed that ICT integration in classrooms is not positively received by many teachers, as they view ICT as a chore activity that is not directed at their core teaching goals. Sugar, Crawley and Fine (2004) recognized that teachers need to have personal reasons for integrating technology. Consequently, when they were already satisfied with their results, they did not have any incentives to integrate ICT in their classrooms.

As in any domain, the improper integration of technology in mathematics classrooms has a long history. Much research from the 1990s was focused on presenting cases of inadvertent use of technology in mathematics education. For instance, Wenglinsky (1998) reported on cases of inappropriate uses of technology in mathematics classrooms, emphasizing that only by deploying adequate pedagogies can teachers help their students perform better in mathematics through ICT. 
Later the mathematics curriculum, topics, and problems changed with the integration of new technologies. Developed around mathematical topics, technological tools designed from pedagogical perspectives were capable of offering effectiveness in supporting students' efforts to understand mathematics (Chazan, 1999). Hodgson (1996) mentions the necessity of mathematics teachers discriminating skills of minor importance from the essential skills. The role of teachers is changing with the advent of introducing technology in classrooms (Goos, Galbraith, Renshaw \& Geiger, 2000). In this respect, computers might help to focus attention on those skills that are considered important.

Therefore it is vital that adequate educational software specific to mathematics teaching and learning be put into place. In this sense, researchers such as Dreyfus (1993) and Yerushalmy (1999) have offered specific principles for designing mathematics. Another problem with software agency is the great number of software products based on drill and practice principles to the detriment of software focused on higher-order thinking skills. Although the drill and practice products might be attractive and easy to use, they do not enhance students' abilities to reflect and find adequate answers. The software products are based mainly on a mechanical way of generating standard answers. For instance, calculators do mathematics for students but they do not teach students to think mathematics (Ronau et al., 2008).

Sometimes innovations are poorly implemented by being adopted uncritically and without paying attention to the specific local settings. For instance, Kaput and Thompson (1994) criticize the passivity of mathematics educators in implementing educational technology:

\footnotetext{
In some ways, the mathematics education community participates in the same conservative attitude as do schools. With few exceptions, the mathematics education community, and especially researchers, have had a passive attitude towards technology. The latest technological innovation, often a tool created for another audience and set of purposes, is too commonly accepted uncritically, leading to sometimes awkward marriages between learning environments and technological innovation or to retrofitting curriculum and instruction to accommodate the innovation. (p. 681)
}

Similarly, Cavanagh and Michelmore (2000) mention that learners tend to uncritically accept graphical images, without relating other sources and ways of information and communication. Hershkowitz and Kieran (2001) noticed that often secondary school students obtain graphical representations from computer programs without considering the algebraic properties of the functions. In particular for the mathematics classroom, Healy and Hoyles 
(2001) noticed that technology poses particular challenges as using ICT was not a guarantee of successful instruction.

Hew and Brush (2007) attempted to create a literature review around the barriers with integrating technologies. Some of these were: a) resources, b) institution, c) subject culture, d) attitudes and beliefs, e) knowledge and skills and f) assessment. Barriers to providing adequate resources involved outdated technologies, lack of adequate training, lack of personal support for maintenance and were considered a major issue in integrating technology.

In order to describe difficulties that teachers encounter in implementing technologies in classrooms, Ertmer (1999) introduced the notion of a first-order barrier and a second-order barrier as a way to locate if difficulties are generated from teachers or from external factors. According to this distinction, first-order barriers are difficulties external to teachers (e. g. lack of computers and software) while second-order barriers are difficulties internal to teachers (e. g. the teacher is not familiar with a specific software). These levels of difficulty are useful for a systematic analysis of the challenges encountered by teachers and learners in classrooms.

Once the barriers are known then the next step is to address them, but how? Fuglestad et al (2010) shows that challenges are better tackled when they are investigated together as a school team. In the end these challenges would be conducive to developing a culture for inquiry approaches. As Gopalakrishnan (2006) states, "Individuals from both educational and technical orientations can support teachers with technology integration as long as they are able to 'translate' between the two domains and work with users of varying technical abilities" (p. 54). In studying exemplary teachers using the TPCK, Grandgenett (2008) recommends that, in order to provide adequate training for in-service teachers, the goals of the instruction should flexibly target teachers to help foster their skills and attitudes in using technology in thoughtful ways.

\section{Methodology}

This research is a qualitative study based on case studies (Creswell, 1998) of a large secondary urban school from Toronto. The school has a large majority of new immigrant students from upper-middle class, almost all of them coming from East Asian and South Asian countries. Three secondary mathematics teachers with over 15 years of experience participated in this study. They were not only very experienced mathematics teachers but also had extended experience and positive attitudes towards using technology in mathematics 
classrooms. For this study, their pseudonyms are Lawrence, Cecilia, and Mark. Lawrence had an undergraduate in mathematics, Cecilia a master degree in mathematics and Mark had started a PhD in mathematics. All of them had over ten years of teaching in this public school.

Data were collected from interviews, class observations and document analysis. For each teacher, it was at least a two hours interview and over 20 hours of classroom observations. Discussion with the mathematics teachers ranged across different modalities entailed by the integration of computer technology in mathematics curriculum. Teachers' practices varied according to technical and curricular settings. Therefore, a considerable amount of time reading different curricular and educational research literature was completed for the purpose of understanding various solutions designed by these teachers for their classrooms. Also, reflection of teaching acts and critical evaluation of the interactions between teacher, students and group activities were needed in order to understand the role of ICT in the mathematics instruction. In these stages, building, openness and the sense of sharing were essential.

Data analysis were structured on the four level of analysis developed by Niess (2008) listed earlier in this paper.

\section{Findings}

In the following, I will present the challenges encountered by the secondary mathematics teachers in the four main sections: a) overall conceptions; b) teacher instructional difficulties; c) student difficulties; and d) technological and curricular issues. These sections are structured according to the data analysis developed from Niess'(2008) theoretical framework.

\section{Overall conceptions}

First level challenges were about teachers' overall conceptions. As mentioned, these secondary mathematics teachers were not only experienced pedagogues, but also had a lot of expertize and showed very positive attitudes towards integrating ICT in their classroom. As these teachers shared a common goal in clearly wanting to use ICT in their classrooms, they differed in their conceptions of how. More exactly, they had a) a dissimilar pace in integrating technology in their classrooms, b) unalike roles for the role of technology in mathematics education, and c) different ICT tools adopted for this purpose. 
The teachers regularly used ICT in their classrooms but adopted a different pace in their classroom. For instance, Mark was a very early adapter of technology. He was willing to try new gadgets or software for his classrooms at a very fast rate. It was enough for him to hear some general ideas about a specific technology and in short time Mark would try these in his classrooms, as long as the perspective of employing that technology was interesting enough for him. As expected, sometimes this was a bit inconvenient, as he had some moments when he would lose some curriculum time. Clearly, setting new technologies for his students required some time in understanding the technical concepts, gauging the mathematical concept solved by these devices, reflecting on the possible pedagogical outcomes, and trying to improve the new attempts for the future attempts.

The other teachers did not have the same fast pace as Mark in adopting new technologies. Although he was the head of the department, he couldn't convince everyone to use ICT in their classrooms. On the contrary, some mathematics teachers from his department still had a negative attitude towards the use of ICT and were reluctant to use technology in their classrooms, despite being urged by Mark and other colleagues.

Lawrence had a positive attitude towards technology but he was a late adapter of ICT. Lawrence was very cautious of learning new ICT devices and software and only after several people advised him about the positive outcomes of these devices, was he willing to learn and apply them in his classrooms. He was reluctant to waste time in his classroom if an ICT device had glitches. As teachers had limited technical support, Lawrence was sometimes anxious of various requirements of the new software. He noticed that, consistently, teachers were on their own when they used ICT in classrooms. Having an expert technologist or another colleague on his shoulder to help him during classes would only occur in exceptional circumstances, and he felt as a result a large number of mathematics teachers might be fearful of technology. If teachers had to work with technology on their own then rigorous preparations were required to implement computer technologies in classrooms, and he added that teachers need to help each other to adapt to new technologies:

If people are comfortable with it, they might use it... Secure enough to go to the classroom! Otherwise, they might look stupid and they might not know how to use it... We help each other; we try to help other people but teachers are on their own. They have to learn by themselves, practice by themselves, and learn how to do by themselves. This takes time and effort. You have to learn the technology, how to set it up and how to work it out. 
There was some disagreement between the two teachers on the pace of introducing ICT in classroom. For instance, Mark considered that Lawrence was too restrained with his attempts of learning ICT for his classrooms. He felt that as long as teachers were mentoring each other, they would learn to adapt these technologies to their own pace, style, and would start endeavouring to use new techniques in their classrooms. Yet he noticed that despite Lawrence's willingness to use ICT for his teaching, the desire to master every minute detail would delay his plans of integrating new technologies into classrooms:

\footnotetext{
When I tried to convince him to use computer technology in classroom, he was saying 'No, I have to learn it first.' But he did make an effort, a few years ago, when I asked him to use Fathom in data management classes. He made the effort, but he did it in his way. He learned it first and then he studied it in class. But he realized that I was right in the first place. That he really did not know it as an expert... He needs to know something, a little bit; how to turn it on and how to run the program. That's about it. Now he is doing it. He does not need to be an expert in that specific technology. Nobody needs to be an expert but everyone has to take the risk.
}

Cecilia was an early adapter of technology. She would prefer to use computers every class. She uses SMART Boards and PowerPoint almost every class to briefly point her pedagogical aspects for the new lessons. Cecilia avoids giving students too many details. Instead, she likes to let her students access computers and learn on their own pace the digital items they believe they need the most. She would avoid using portable device such as graphic calculators. She avoided using the portable device. Instead, she preferred to use desktops as they are safer and more conducive for learning mathematics.

Lawrence and Cecilia had different opinion about the role of portable devices. Lawrence, for instance, centred most important aspects of his teaching around graphic calculators. He used them for both grade 9 applied mathematics students and for grade 12 students placed in the Advanced Function courses. However, he mentioned that he used them differently. For grade 9 students, the use of graphic calculators helped them visualise numerical values and linear functions, while for the grade 12 students, the use of graphic calculators helped them understand concepts and proofs. Thus Lawrence considered them very handy, while Cecilia would avoid them as much as she could. Mark was somehow in the middle, considering them portable, but difficult to update. For this reason, he believed that, overall, computer software remains more up-to-date and helpful for him.

Thus while technology had a different role for these teachers, there were things they shared. All of them agreed on the large potential of technologies to visualise different mathematical problems and theorems and accepted that the SMART Boards were helpful. 
Although Lawrence saw the use of SMART Boards as very prone to technical glitches and unsuitable for his pedagogy for grade 12 students.

The teachers experienced some dissonance between their theoretical and practical conceptions. It was observed that they did not try to implement mathematical software that was from free public domain (i.e. GeoGebra). As well, as they were recently informed about Web 2.0 technologies, but it appeared that these technologies required new teaching approaches that the teachers did not know and did not give them any importance.

\section{Teacher Instructional Difficulties}

As expected, teaching mathematics in secondary classrooms was challenging for these teachers and ICT was part of instructional challenge. Mark viewed mathematics as the art of thinking and living as a mathematician and wanted to offer this view to his students. Most of the students were really excited about his passion for teaching mathematics at the highest intellectual standards. Some students were not interested with all the proofing aspects and, at times, they were overwhelmed by his passionate and challenging pursuits. On the other hand, Cecilia and Lawrence did not challenge them enough, and the students were bored, off task, and more or less boisterous.

For teachers, the role of technology in teaching varied. For instance, Cecilia often used PowerPoint slides for teaching, while Mark never attempted to use slides to explain a concept. Lawrence was in the middle, as he often used PowerPoints for his grade 9 students.

Mark considered that some aspects of abstract mathematics should remain as it is and shouldn't be taught with technology. He felt these abstract parts of the curriculum should remain optional only and should not be eliminated by fears that they were too challenging and some students might not understand. Cecilia did not attempt teaching much of the abstract part of mathematical content. Instead, she provided digital resources or textbooks to her students and let them access the material at their own pace. Again, Lawrence was in the middle, as he gave some hints about proofing but he did not try to teach them in minute detail.

There were also some challenges that Mark had as head of department:

I would like to have the whole picture. I want to know what the school is... Where the main efforts are going. ... What the ministry is trying to do. I am trying to be aware of these changes in the curriculum, and changes to approaches of delivering the curriculum. ... To give you particular examples, about ten years ago, the ministry introduced new assistant evaluation approaches. It was written into the curriculum how we are supposed to 
evaluate the students. Not just what the students are supposed to know at the end of each course, but how it is supposed to be delivered and how it is supposed to be evaluated. As I said, this was ten years ago and the debate is still on. There are schools where still this has not been accepted.

As head of department, Mark often felt that the structure of his public school was sometimes too bureaucratic and difficult to adapt to students' needs. As an example, Mark related how he recently struggled to offer an enrichment preparation program in mathematics for grade 12 students of his school, in order to give more academic opportunities to students focused on studying mathematics. He mentioned that this plan was seriously challenged by other curriculum leaders from his school. He was disappointed that he had to put a great amount of effort, in order to persuade the other school leaders to accept his plan:

\footnotetext{
There are challenges, absolutely. One of the challenges is that I cannot simply do what I want to do. Because the bottom line is when we want to do this initiative, which requires the entire school, the administration has to be aware of it. When the administration has to be aware of it, the entire administration team usually has input. Some committees usually want to have input. For instance, we came up with an idea of offering enrichment classes for grade 12 a year ago. The way we wanted to do it was to offer an advanced placement, calculus and stats courses. We faced a lot of opposition. I am not going into details. For some reason, the other curriculum leaders were strongly opposing them. Not all of them, but part of them seemed to be opposing this idea... So, the challenges are whenever you come up with an idea, it goes outside of the department. Even if we agree within the department, things are usually bumpy.
}

While there is a large theoretical consensus about the instructional benefits of ICT, sometimes the ICT did not help these teachers. For instance, when the three teachers used technology to explain and visualise geometrical concepts, they noticed that sometimes the students did not understand the proofing part. Sometimes the students accepted too easily the graphical parts of the exercise without critically interpreting the results. To solve these issues, Mark tried to teach the students to be critical towards these visual aspects in order to ensure that these mathematics simulations would offer meaningfulness.

As well, some technologies were not always appreciated by the students. For instance, although graphic calculators were appreciated for portability, students easily got bored with them and did not try to use them in a meaningful way. This was especially the case for the old graphic calculators. On the other hand, when the students used more complex devices such as computer desktops, they had different opportunities to access other software and digital resources and sometimes they did not stay focused with the lesson. For instance, despite of being instructed to solve a specific problem, grade 9 mathematics applied students often used computer desktops to check their emails, Facebook accounts and YouTube videos. 


\section{Student Difficulties}

Although teaching at the same school, the teachers taught very different classrooms. For instance, Lawrence was teaching a grade 9 mathematics applied class with most of the students' mathematical knowledge being actually well below grade 6 level. Lawrence and Mark each had one classroom of grade 12 students taking Advanced Functions. These students were well accomplished academically and were taking this course for admission to university. Cecilia taught two classes and Mark taught one class of Data Management course to grade 12 students who, on average, were slightly below to those registered for the Advanced Functions course but well above to those registered for the mathematics applied classes. As for the Calculus and Vectors advanced class, Mark was the only teacher who taught this course, with students who were the most gifted mathematically on their year.

Because of students' lack of mathematical content and motivation, teaching students from grade 9 applied mathematics posed great difficulties. Many of the students had problems working with decimals and some with whole numbers. As well, they had problems with English in reading and writing and, therefore, the teacher had a difficult time keeping them on task. Some students were using the graphic calculators and computers carelessly by dropping them on the floor. On some occasions, the students from the grade 9 mathematics applied course were not able to use graphic calculators for assignments. Instead, they tried to avoid the use of graphic calculators and solve the problems on paper only. When they were brought into the computer lab, they attempted to use technology for things unrelated to learning mathematics. Therefore, the teacher had a hard time trying to convince them to keep their focus on working with the mathematical software.

When Lawrence was asked about the level of understanding of the grade 9 students, he mentioned that "they seem to understand concepts but they cannot do anything with them". He was aware of the process of selecting students in applied mathematics courses and believed that the current strategies of integrating technology are getting more effective for them:

\footnotetext{
Nine applied are never strong. But I think that [by integrating technology], they get to learn more. I cannot prove that. But I think that their EQAO scores are a little better, which means that the program is actually working. The classes are going now a little smoother and the students are less nasty, mean, or belligerent. They are more focused if they are going better.
} 
When I asked Lawrence about his grade 12 students who registered for the Advanced Functions course, he stated that being at this stage means that they will pursue higher education degrees. They were described as gifted and able to accomplish complex mathematical problems:

This is a different matter. I treat them like university students. I try to give them interesting problems. I try to challenge them. I try to give them problems that are not obvious.

Something that requires a bit of thought so they can play around with it. ... The textbook is pretty straightforward. I try to make them more open-ended.

Asked if the students understood their lessons, he praised their results and dedication:

Most of the time they do this right away; it's no problem for them learning and doing it. It's pretty straightforward... It's hard to judge but based on tests, most of them do well. Most of the kids are well prepared. They know the stuff; they get at least 80, 85 percent. If they do not know, they come and ask me, whatever the misunderstanding is. Like I always go back, review, and repeat. I constantly repeat. Whenever one comes up you do.

He thought that most of the students understood the Advanced Function course, and, because almost all of his students get over 80 to 85 percent, this shows that these students understood the concepts of the course. Also, Lawrence noted that students know how to use computer technologies in their mathematical projects:

Most of them get it. Like the weak students will not get it very well. But the good students will do well. And they will understand. Usually most of them are successful... They know how to graph... They know how to find maxs, mins, and intersections. They know almost everything. Especially for grade 12, there isn't much on calculators they can't do. You know, most of the time it's TI-84 and TI-85.This is what we have. Now we will use more TI-Nspires, whenever it is available.

Students also faced challenges in the Advanced Functions course. Similar to those Calvert, Zack and Mura (2001) reported in their study, where some of the students had problems grasping the mathematical significance of using these tools and were not able to interpret the graphic of the functions that were displayed by graphic calculators. Other students became bored when, throughout their entire course, they used only the old models of graphic calculators such as TI-84 and TI-85. Even though these old graphic calculators could give them adequate support for learning in this course, they became bored with these outdated ICT tools.

Cecilia reported that the students from her two classrooms had different academic backgrounds. The majority of them took the previous course Functions, grade 11, University Preparation (MCR3U) for the academic profile while some of her students took the grade 11 course Functions and Applications (MCF3M): 
In Data Management students are coming with various strengths. 80 percent took in the 11th year Advanced Functions course which is for the academic stream, and the rest of our students took Functions and Applications, so for them their experience with math is weaker than the others so when we teach data management, we do not assume too much and we have the possibility to do that because Data Management is not so algebraic as the Advanced Functions course.

The present course called Mathematics of Data Management depends on students' previous academic backgrounds. More exactly, if students had previous taken mathematics classes from the academic curriculum, they would manage the course more easily, while students from the applied profile would encounter more difficulties to adapt to this course:

\begin{abstract}
It depends on the students. We have some students who are coming from the three year course, the grade 11 Functions. For these students, this is a very easy part of the course. Working with formulas, doing calculations, they are comfortable with that. For other students, who are from the weaker three year program, students coming from the Functions and Applications course, they are having more difficulties; they need to follow multiple steps. It requires a little more analytical thinking and, so, for them, this part of the course is a struggle.
\end{abstract}

Asked about the difficulties that students encounter, she answered that, especially for this project, it is hard to keep them on-track. For her, maintaining a website improves students' focus on tasks and clarifies many ambiguities:

For these students the most challenging is keeping them on-track. They need to be doing work outside of the classrooms in order to be prepared for the next chapters. And so for the findings from one year to the next it depends on the students I got. But some are much better in time management. I can see for some of the students I have right now their time management is a weakness. So this is part of the reason why I maintain the course's website. Because, as I know they must misplace things or they do not have the information they need at their fingertips or in the notebooks. So having a course website as another place where the student can look for information is important to me. There are slides students can look for the information when they are not in class. The reason is to eliminate some reasons to say they forgot these things.

When she was asked about students' expectations, she indicated that sometimes students have problems focusing and becoming engaged in their academic work. Therefore, computer technology might perform an important role of making students more interested in studying mathematics:

\footnotetext{
Sometimes I believe that students just want me to entertain them. They want to be engaged in a lesson and I think this is how technology plays a role in being able to see something move on the screen... Somewhat more interesting than watching me drawing diagrams on the board... I think it also enables me to do more examples informally. And also I can do more examples quickly.
}

The students from the Calculus and Vectors course had some specific challenges. Being the most advanced pre-university course, it was implied that this course would gather the most advanced students in mathematics. However, not having enough previous 
opportunities to be involved in geometry, this part of the course was extremely difficult for students to grasp. Mark was trying to explain proofing and different ways of reasoning, but due to time constraints this was extremely challenging. The unit was recently redesigned by the Ministry of Education and therefore, the students did not have available software able to cover the whole curriculum. Mark reflecting on these changes had little time to learn by himself and explore what software would be adequate for specific units. He experimented with new software for very short periods of time.

\section{Technical and Curricular Issues}

\section{Technical difficulties}

A considerable problem was the lack of computer technology. While all of the teachers were determined to integrate technology in their classrooms, the school could not afford to have all of these technologies and use them simultaneously. Therefore, as noted in Maor's (2003) study, the IT infrastructure represented a serious problem that teachers had to consider.

Teachers had some problems with technology and with instructing students to use computers. The software generated an important number of challenges. The software was not always able to help students. Cecilia and Mark stated that some units did not offer many possibilities for using computer technology with the students. Each course had some areas where no actual computer technology could have any impact on student learning. Another challenge was mentioned by Mark and Cecilia, when they asserted that the Microsoft Excel is not helping their students much for Data Management. The reasons for this was that, obviously, Excel was designed for office work and not for pedagogical purposes to help high school students learn statistics. Therefore, for Data Management they would prefer the Phantom software as they needed to use very few commands in Excel.

When I asked about the administration, Lawrence mentioned that the great need of technology makes difficult for any school to keep up with students' demands and with the last trends:

The administration supports us because they give us money to buy computers... We always want more. The more labs you have, the more computers you want. It is never enough. What they do, they give you something, as much money they can afford to get you right. We stand on technology. Most teachers seem to be quite open to technology, to use technology. 
When asked about different technologies that he might consider in teaching for the next semester, Lawrence mentioned Gizmos as an important tool for assessment and instruction for use in his classrooms. He appreciated that Gizmos can give students detailed feedback and recommend some exercises to revise mathematical knowledge. However, he mentioned that Gizmos were not always well designed and sometimes the ideas of tutorials embedded in Gizmos lessons did not fit with students' needs. As well, he mentioned that not having enough computers was a serious issue for these tutorials, as there was only one mathematics lab in the school.

\footnotetext{
Graphically, they [Gizmos] visualize, they do problems. And there are a lot of problems, a lot of Gizmos. I used a few, but I think that this is going to be a thing in the future. Using these little programs called Gizmos. But that requires that the kids have individual computers. I can bring one computer only in a regular classroom, so I have to bring them to the lab. And to have everybody work on that it is a bit of a problem. There are not many labs. It's only one lab. You got to share.
}

Cecilia mentioned that, in her case, because she meets her students each working day, using Web 2.0 collaborative technologies might not be so important and they do not offer adequate support for a public educational setting.

\footnotetext{
I like the idea of Web 2.0 but I do not have personal experience with Web 2.0 technology. I have been in a workshop where they showed how to contribute to a wiki. In my personal experience, I am not convinced that it is beneficial to use it in my teaching. Because I see my students from Monday to Friday, so if they have a question they might be more likely to talk to me to add something to the discussion. Maybe in the future I will incorporate but not in this moment.
}

In addition, there were some issues around the manipulation of the technological devices. For instance, some students dropped the graphic calculators on the floor and this could reduce their functionality over time. Some graphic calculators ran out of batteries and some had deteriorated. The teachers used different versions of the software from that used in the examples in the textbooks. However, these were reasonable challenges and the teachers were working hard to fix them.

\section{Curricular Challenges}

There were many changes that gave a hard time to the mathematics teachers of this school. For instance, Mark and Lawrence considered that when the Ministry of Education eliminated the grade 13 program from Ontario secondary schools, this reform has irreversibly diminished the level of preparation of the students graduating from secondary schools. For instance, Mark described his concern: 
The curriculum changes, so it may not be simple to compare the level of achievement but, when I started working in 1997, we still had that five-year program. The students were more mature. Then we had to change the programs. There are now visible changes in our school.

Another discrepancy was noticed in the Advanced Functions course, where many problems from the current textbook were solved with Geometric Sketchpad, but Mark chose to solve these problems using Fathom software, which was not supported or was not mentioned at all in the textbook. Mark argued that an updated textbook for this course would make the Geometric Sketchpad software less necessary and would include the Fathom software.

Another example was the use of graphic calculators. With different graphic calculators in use some principles and ideas of use are common, the newer models have new features requiring more complex knowledge. For instance, the introduction of a new model, TINspire, presented some challenges for both teachers and students because of the many more features compared to the older models the TI- 83 and TI-84. This required a lot of time and effort on the part of teachers, especially when they had high expectations of themselves, as it was the case for all of them.

Some curriculum areas were not covered with current software products. These made teachers feel uneasy. For instance, in the Calculus and Vectors course, there was no software to cover the second half of the course. Therefore, Mark had to use several software products for different lessons. This approach could not be followed by many teachers as becoming familiar with the content of this course was not covered by any workshop or seminar and was an individual effort.

The three teachers displayed a strong understanding of the challenges that might appear in the use of technology in mathematics instruction. Overall the process of adapting technology in mathematics classrooms and the adequacy of the curriculum posed various degrees of challenges that were common to all teachers. Sometimes there were problems with the technology and sometimes the curriculum did not afford much support for learning by using the present software. Still, the teachers felt that the technology offers realistic opportunities for supporting students' learning and that they could use technology for teaching and assessments. 


\section{Discussion}

\section{Summary of Challenges}

The first level challenges of teachers' overall conceptions of integrating technology in classrooms, involved different paces of integrating technology, various opinions about what should be taught or not with ICT, and different opinions about ICT portability.

The second level challenges of teachers' instructional difficulties using the TPACK framework are located at the intersection between pedagogy, content, and context. Some challenges were caused by the change of software and hardware. When software or hardware used by teachers changed, then time was needed to update their skills.

The third level on students' challenges involved the adaptation of general technology skills to specific mathematic tools (Ronau et al., 2008).

The fourth level involving technical and curricular issues using the TPACK framework are found in the intersection between technology and context. Some limitations were due to challenges posed by the technology, either hardware or software problems. Teachers commented that financial aspects were a serious consideration in purchasing ICT devices and software as the prices for some products were prohibitive.

In total the challenges in integrating ICT were large and evident in multiple activities: teaching activities, class assignments, interactions between teachers and students, and interviews and discussions about using technology in mathematics. The teachers mentioned that, in spite of these challenges, the role of technology was still engaging for their students and that computer technology is needed in their classrooms.

\section{Final Comments}

Why are so few teachers currently integrating technology in secondary school classrooms (Cuban, 2001), particularly in mathematics classrooms? This study did not explore the root causes that make technology difficult to be integrated in mathematics curriculum, rather it focused on successful practices of integrating technology in mathematics, revealing both individual and institutional challenges that made these attempts possible.

A major problem is that, although the integration of technology in Canadian education has been recommended for almost three decades, in fact this process of integration is still not 
implemented on a large scale. The process of integrating technology has not penetrated every Canadian school as expected. This is due to different reasons. At the beginning, the main reason was the high costs required. Now, it seems to be that the main reason is that the integration of technology is still an option and therefore teachers can delay whenever they wish. Unfortunately, as Mark and Cecilia mentioned, this process of integrating technology in curriculum still remains at the stage of recommendation. This lack of specific deadlines might trigger a lack of planning and clarification for the specific use of computer technology. This might be because of lack of clear guidelines for integrating technology in mathematics classroom from teachers, administrators, or the school board.

Perhaps it might be argued that some software products such as Excel and PowerPoint are easy to use because teachers have been using them in other contexts. However, other software products such as SMART Boards or TI-Nspire Graphic Calculators might be new and require some training. For some specific software products for the mathematics curriculum, such as Fathom or the Geometer's Sketchpad, an extensive period of training is required. These are cases when software requires an extensive period of learning, training, and assistance in teaching them in the classroom and therefore teachers should consider them attentively.

Professional development programs for mathematics teachers should provide more opportunities to help the teachers integrate technology in the classroom. Mark mentioned that the workshops and seminars only trigger an interest in a specific problem. Indeed this is the case for an experienced mathematics teacher who has already taught for some time using computer technologies in the classroom. But the problem is different for a teacher who has not yet tried to use computer technology in their teaching.

Technical support is very important. For teachers who have strong expertise in computers, it was fine to have technologists from outside the school to support them. However, for teachers who were new to technology, this could be frightening. Therefore, for new teachers, maybe the technological support should be embedded in the school in order to encourage them to efficiently use technology in classrooms.

It is important to have teachers skilful in mastering computer techniques and able to show these to students. In this research, it was important to have in a mathematics department a critical number of teachers who were interested in integrating technology in the classroom. 
Teaching with technology requires interactions with colleagues and teamwork. Therefore, it is very important to establish mentoring relationships with teachers who are already comfortable with computers in teaching mathematics. It is essential to establish collaboration between technical support staff and teachers in order to solve various technological issues. The administration of the school should support efforts to integrate computer technologies in mathematics classrooms. Likewise, time should be allowed for designing and integrating technology in classrooms (Mishra \& Koehler, 2007). In addition, a more specific agenda for sharing ideas, skills, and computational resources should be considered.

Teaching is an iterative process (Koehler \& Mishra, 2008) and, as the models of Rogers (1996) describe, the technology takes different stages of integration. Therefore, the process of integrating technology requires sustained leadership effort that needs to be carefully planned. More precisely, teachers and administrators should consider a long term perspective in plans to implement technologies into classroom.

Technology is changing fast and therefore it will always remain a challenge to implement in purposeful way in mathematics education. As Grandgenett (2008) recommends, in order to provide adequate training for in-service and pre-service teachers, the goals of the instruction should flexibly target teachers to help foster their skills and attitudes in integrating ICT in mathematics classrooms in thoughtful ways.

The technology changed the control and the management of classrooms. For instance, by making digital resources available to students, the students had access to them to learn without any effort from teachers. In their turn, the teachers interacted with students only at critical points when they needed specific advice or coordination. These strategies developed over time. Koehler and Mishra (2008) suggest, the preparation of teachers should be a spiral process, starting first with technologies that are simple and familiar to them. They might extend afterward with products of increasing difficulty. Therefore, aspects of and strategies for time management, interaction, and collaboration should be carefully considered in integrating technology. 


\section{References}

Anderson, J. R. (1992). Intelligent tutoring and high school mathematics. In Proceedings of the 2nd International Conference on Intelligence Tutoring Systems (pp. 1-10). Montreal: Springer-Verlag.

Calvert, L. G., Zack, V., \& Mura, R. (2001). Children's Proving. Proceedings from Canadian Mathematics Education Study Group, Annual Meeting, University of Alberta, Edmonton, Alberta, May 25 - 29, (pp. 41-46).

Cavanagh, M., \& Mitchelmore, M. (2000). Student misconceptions in interpreting basic calculator display. In T. Nakahara \& M. Koyama (Eds.) Proceedings of the 24th PME International Conference, vol. 2, 161-168.

Chazan, D. (1999). On teachers' mathematical knowledge and student exploration: A personal story about teaching a technologically supported approach to school algebra. Journal International Journal of Computers for Mathematical Learning, 4(2), 121-149.

Creswell, J. W. (1998). Qualitative inquiry and research design. London, UK: Sage Publications.

Cuban, L. (2001). Oversold and Underused: Computers in the Classroom. Cambridge, MA: Harvard University Press.

Dreyfus, A. (1993). Selecting Appropriate Strategies for Laboratory Teaching: a Problem in Teacher Training. European Journal of Teacher Education, 16(3), 257-270.

Drijvers, P, Kieran, C \& Mariotti, M.A. (2000). In C. Hoyles \& J. B.Lagrange (Eds.) Mathematics education and technology-Rethinking the Terrain (pp. 89-132. New York: Springer.

Ertmer, P. A. (1999). Addressing first- and second-order barriers to change: Strategies for technology integration. Educational Technology Research and Development, 47(4), 4761.

Fuglestad, A. B., Healy, L., Kynigos, C., \& Monaghan, J. (2010). Working with teachers: Context and culture. In C. Hoyles \& J. B.Lagrange (Eds.) Mathematics Education and Technology-Rethinking the Terrain (pp. 293-310). New York: Springer.

Goos, M., Galbraith, P., Renshaw, P., \& Geiger, V. (2000) Reshaping teacher and student roles in technology-enriched classrooms. Mathematics Education Research Journal,12, 303-320.

Hershkowitz, R., \& Kieran, C. (2001). Algorithmic and meaningful ways of joining together representatives within the same mathematical activity: An experience with graphing calculators. In Psychology of Mathematics Education Conference (Vol. 1, pp. 1-96).

Hodgson, B. (1996). The roles and needs of mathematics teachers using IT. In D. Watson \& D. Tinsley (Eds.) Integrating Information Technology into Education, (pp. 27-37). Chapman \& Hall, London, UK.

Hoyles, C., \& Noss, R. (2003). What can digital technologies take from and bring to research in mathematics education? In A. J. Bishop, M. A. Clements, C. Keitel, J. Kilpatrick and F. Leung (Eds), Second International Handbook of Mathematics Education (Vol. 1, pp. 323-349). Dordrecht, the Netherlands: Kluwer Academic.

Gopalakrishnan, A. (2006). Supporting technology integration in adult education: Critical issues and models. Adult Basic Education: An Interdisciplinary Journal for Adult Literacy Educational Planning, 16(1), 39-56.

Grandgenett, N. F. (2008). Perhaps a matter of imagination: TPCK in mathematics education. In AECT Committee on Innovation and Technology (Ed.), Handbook of Technological Pedagogical Content Knowledge (TPCK) for educators (pp. 145-165). New York: Routledge.

Healy, L., \& Hoyles, C. (1999). Visual and Symbolic Reasoning in Mathematics: Making Connections With Computers?. Mathematical Thinking and Learning, 1(1), 59-84. 
Heid, K. (2005). Technology in mathematics education: tapping into visions of the future. In W. J. Masalski (Ed.), Technology-Supported Mathematics Learning Environments: NCTM 67th Yearbook. Reston, VA: NCTM.

Hew, K. F., \& Brush, T. (2007). Integrating technology into K-12 teaching and learning: Current knowledge gaps and recommendations for future research. Education Technology Research Development, 55, 223-252.

Kaput, J. (1992). Technology and mathematics education. In Grouws D. (Ed.) Handbook of Research on Mathematics Teaching and Learning. New York: Simon and Schuster Macmillan. pp. 515-556.

Kaput, J., Noss, R., \& Hoyles, C. (2008). Developing new notations for a learnable mathematics in the Computational Era. In English, L. (Ed) Handbook of International Research in Mathematics Education, (pp. 693-715). Mahwah, NJ: Lawrence Erlbaum.

Kaput, J., \& Shaffer, D. W. (2002). On the development of human representational competence from an evolutionary point of view: From episodic to virtual culture. In K. Gravemeijer, R. Lehrer, B. van Oers, \& L. Verschaffel (Eds.), Symbolizing, modeling and tool use in mathematics education (pp. 269-286). Dordrecht, The Netherlands: Kluwer Academic.

Kaput, J., \& Thompson, P. W. (1994). Technology in mathematics education research: The first 25 years in the JRME. Journal for Research in Mathematics Education, 25(6), 676684.Retrieved at April 282009 from http://www.jstor.org/stable/749579b

Kelly, D., \& Tangney, B. (2006). Adapting to intelligence profile in an adaptive educational system. Interacting with Computers, 18(3), 385-409.

Koehler, M. J., \& Mishra, P. (2009). What is technological pedagogical content knowledge? Contemporary Issues in Technology and Teacher Education, 9(1), 60-70.

Li, Q. (2007). Student and Teacher Views about Technology: A Tale of Two Cities? Journal of Research on Technology in Education, 39(4), 377-397

Magala, S. (2006). Virtual blood, real media, Kritikos, 3. Retrieved July 22, 2010 from http://intertheory.org/magala.htm

Maor, D. (2003). The teachers' role in developing interaction and reflection in an online learning community. Education Media International, 40 (1/2), 127-137.

McCrory, R. S. (2006). Technology and teaching: A new kind of Knowledge. In E. A. Ashburn ans R. E. Floden (Eds.) Meaningful Learning using Technology (pp. 141- 160). New York: Teachers College Press Columbia University.

Mishra, P., \& Koehler, M. J. (2007). Technological Pedagogical Content Knowledge (TPCK): Confronting the wicked problems of teaching with technology. In R. Carlsen et al. (Eds.), Proceedings of Society for Information Technology \& Teacher Education International Conference 2007 (pp. 2214-2226). Chesapeake, VA: AACE.

Mishra, P., \& Koehler. M. J. (2008). Introducing Technological Pedagogical Content Knowledge. Proceeding for the Annual Meeting of the American Educational Research Association, New York City, March 24-28, 2008.

National Council of Teachers of Mathematics (NCTM). (2000). The Technology Principle. Retrieved June 24, 2014 from http://standards.nctm.org/document/chapter2/techn.htm

Niess, M. L. (2008). Guiding preservice teachers in developing TPCK. In AECT Committee on Innovation and Technology (Ed.), Handbook of Technological Pedagogical Content Knowledge (TPCK) for educators (pp. 223-250). New York: Rutledge.

Plair, S. K. (2008). Revamping professional development for technology integration and fluency. The Clearing House: A Journal of Educational Strategies, Issues and Ideas, 82(2), 70-74.

Rogers, E. M. (1996). Diffusion of innovations. New York: Free Press. 
Ronau, R. N., Niess, M. L., Browning, C. A, Pugalee, D., Driskell, S. O \&. Harrington, R. (2008). Framing the research on digital technologies and student learning in mathematics. In L. Bell, L. Schrum, \& A. D. Thompson (Eds.) Framing the research on technology and student learning in the content areas (pp. 13-31). Information Age Publishing, Charlotte: NC.

Sangwin, C., Cazes, C., Lee, A. \& Wong, K. L. (2010). Micro-level automatic assessment supported by digital technologies. In C. Hoyles \& J. B.Lagrange (Eds.) Mathematics Education and Technology-Rethinking the Terrain (pp. 227-250). Springer US.

Stoilescu, D. (2011). Technological Pedagogical Content Knowledge: Secondary School Mathematics Teachers' Use of Technology. Unpublished Doctoral dissertation, University of Toronto.

Stoilescu, D. (forthcoming). Technological Pedagogical and Content Knowledge: Case studies of secondary school mathematics teachers' use of technology. Journal of Educational Computing Research.

Stoilescu, D. (forthcoming). Technological Pedagogical and Content Knowledge: Secondary school mathematics teachers' use of technology. Fields Mathematics Education Journal

Sugar, W., Crawley, F., \& Fine, B. (2004). Examining Teachers' Decisions To Adopt New Technology. Educational Technology \& Society, 7(4), 201-213.

Van Herwaarden, O., \& Gielen., J. (2002). An approach for the effective integration of computer algebra in an undergraduate calculus and linear algebra course. Proceedings of the 2nd International Conference on the Teaching of Mathematics, Hersonissos, Creta, Greece.

Wenglinsky, H. (1998). Does it compute? The relationship between educational technology and student achievement in mathematics. Princeton, NJ: Policy Information Center, Research Division, Educational Testing Service.

Yerushalmy, M. (1999). Making Exploration Visible: On Software Design and School Algebra Curriculum. International Journal of Computers for Mathematical Learning. $4(2-3), 169-189$ 